\title{
Polygraphic studies of the effect of nitroglycerin in patients with ischaemic heart disease
}

\author{
Toshitami Sawayama, Masaru Tohara, Hiroshi Katsume, and Shoso Nezuo \\ From the Department of Cardiology, Kawasaki Medical College and Hospital, 2-1-80, Nakasange, Okayama \\ 700, fapan
}

Polygraphic recordings were made before and after $0.6 \mathrm{mg}$ of sublingual nitroglycerin in 20 normal subjects and in 20 patients with ischaemic heart disease.

The following effects of nitroglycerin were observed in both groups: shortening of ejection time, prolongation of pre-ejection period and also of isometric contraction time unrelated to decrease in systolic blood pressure, and increase in heart rate; in the apex cardiogram, retraction of the systolic wave and diminution in amplitude of the $A$ wave which approached the ventricular wave; in the carotid arterial pulse, decrease in the level of the dicrotic notch, disappearance of the tidal wave, and augmentation of the dicrotic wave.

When compared with the normal group, pre-ejection period and isometric contraction time were significantly more prolonged $(P<0.05)$ in the diseased group, the blood pressure was more reduced, and the heart rate showed a greater increase.

These alterations in polygraphic parameters after nitroglycerin reflect the decrease in stroke volume and blood pressure, and therefore of cardiac work, induced by the drug.

The data suggest that nitroglycerin more obviously reduces cardiac work (and presumably myocardial oxygen consumption) in the diseased group than in the normal group. A similar trend was evident after the administration of amyl nitrite in a study previously reported by the authors.

The value of noninvasive (polygraphic) methods for evaluating abnormalities of cardiac function in disease states may be enhanced by studying changes induced by vasoactive drugs. Nitroglycerin is of particular interest in this regard because its effects are largely on the peripheral circulation, and because it is in common clinical use.

Nitroglycerin is a 'coronary dilator' but the effectiveness of this agent in angina pectoris is largely due to its reduction of blood pressure, and therefore of cardiac work (Gorlin et al., 1959; Parker, West, and Giorgi, I97I). There have been some comparisons of the effects of this drug on the cardiovascular system in normal persons and in patients with ischaemic heart disease. However, all previous reports have used direct, invasive methods (Gorlin et al., 1959; Parker et al., 197I). There is, as yet, no report dealing with haemodynamic effects of the drug, as judged by noninvasive polygraphic methods.

In the present study, various parameters of polygraphic recordings were compared before and after Received 30 May 1973. the administration of nitroglycerin, and differences between the responses of normal subjects and of patients with ischaemic heart disease were studied.

\section{Subjects and methods}

Twenty normal men were selected for our study. They were over 40 years of age and had no heart disease as judged by precise physical and laboratory examination, including the Master's double two-step test. Twenty men with ischaemic heart disease were selected for comparison. They all had past histories of myocardial infarction, or had angina of effort, and all had a positive Master's test (using a criterion of $\mathrm{I} \mathrm{mm}$ ST segment depression). They all had normal sinus rhythm without conduction disturbance, and had no congestive heart failure, hypertension, or valvular disease. Drugs that would directly influence cardiac function were discontinued before the study.

All studies were carried out with the subjects in the supine position and in a basal, postabsorptive state. In each subject, simultaneous recordings of the apex cardiogram, low- and middle-frequency phonocardiogram, electrocardiogram (lead II), and the indirect carotid pulse were made on a multichannel, jet writing unit (Elema-Schonänder) at a paper speed of $100 \mathrm{~mm} / \mathrm{sec}$, 
with time markers indicating 0.01 sec. Heart sounds and apex cardiogram were recorded over the apex with a contact microphone. The indirect carotid pulse was obtained with a crystal pick-up connected to a pulse transducer. A representative polygraph recording is shown in Fig. $\mathbf{I}$.

Tracings were recorded during a control period and then repeated at $4,6,8$, I0, and 12 minutes after the administration of $0.6 \mathrm{mg}$ nitroglycerin sublingually. In addition, blood pressure was measured at the end of each recording.

The following polygraphic data were obtained before and after nitroglycerin in both groups of subjects (see Fig. I): systolic and diastolic blood pressure (BPs and $\mathrm{BPd})$; heart rate (HR); left ventricular ejection time and ejection time index (ETI $=E T+\mathrm{I} \cdot 25 \times \mathrm{HR})$; Q-U interval (from the $Q$ wave to the upstroke of the carotid artery pulse); Q-U index ((Q-U) +0.50 $\times$ HR); I-U interval (from the first heart sound to the upstroke of the carotid arterial pulse) and Q-I interval. The directly measured I-U and Q-U intervals were used instead of the standard isometric contraction time (ICT = interval from first to second heart sound minus ejection time), and pre-ejection period $(P E P=Q-2$ interval minus ejection time), to which they, respectively, correspond, in order to minimize errors in measuring ICT and PEP which are composed of multiple measurements. In addition, corrections for pulse transmission time are unnecessary when Q-U and I-U are used in the same subject, as when studying a drug intervention as in the current experiments. The values of the systolic time intervals were the averages of 5 consecutive cardiac cycles during the maximal effect of the drug. In addition, in the apex cardiogram, changes in the amplitude of the A wave, the atrioventricular interval (A-C interval, from the top of the $A$ wave to the upstroke of the ventricular wave), and the shape of the ventricular wave were observed. Also, changes in wave shape of the carotid arterial pulse and in the level of the dicrotic notch were analysed.

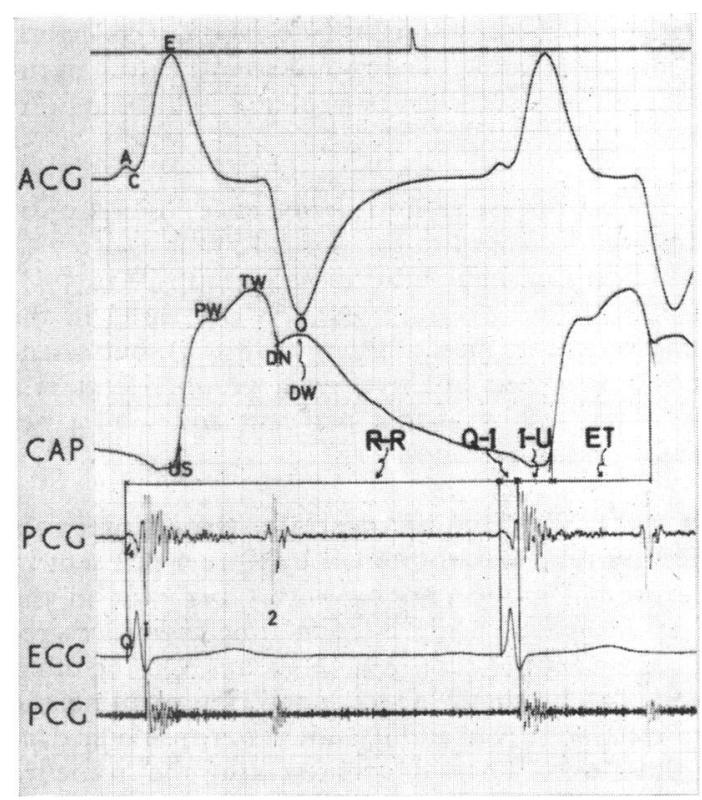

FIG. I $A$ control tracing of the 5-channel polygram and 4 items measured directly on the tracing $(R-R$, $Q-I, I-U$, and ET). ACG, apex cardiogram; $C A P$, carotid artery pulse; $P C G$, phonocardiogram taken at the cardiac apex; ECG, electrocardiogram (lead V5).

\section{Results}

\section{I) Changes observed before and after nitro- glycerin administration}

The Table gives the average values of the maximal

TABLE Maximal percentage changes in various haemodynamic items after administration of nitroglycerin to normal subjects and patients with ischaemic heart disease

\begin{tabular}{|c|c|c|c|c|c|c|c|c|c|}
\hline & $\begin{array}{l}\text { Systolic } \\
\text { blood } \\
\text { pressure }\end{array}$ & $\begin{array}{l}\text { Diastolic } \\
\text { blood } \\
\text { pressure }\end{array}$ & $\begin{array}{l}\text { Heart } \\
\text { rate }\end{array}$ & $\begin{array}{l}\text { Ejection } \\
\text { time }\end{array}$ & $\begin{array}{l}\text { Ejection } \\
\text { time } \\
\text { index }\end{array}$ & $Q-U$ & $\underset{\text { index }}{Q-U}$ & $v-U$ & $Q-I$ \\
\hline \multicolumn{10}{|c|}{ Normal (\%) } \\
\hline $\begin{array}{l}\text { Mean } \\
\operatorname{SD}( \pm) \\
\operatorname{SE}( \pm)\end{array}$ & $\begin{array}{r}-10.7 \\
7 \cdot 2 \\
1.6\end{array}$ & $\begin{array}{r}-0.2 \\
11.6 \\
2.6\end{array}$ & $\begin{array}{r}+20.4 \\
9.8 \\
2.2\end{array}$ & $\begin{array}{r}-14.6 \\
5.9 \\
I \cdot 3\end{array}$ & $\begin{array}{r}-6.5 \\
3.6 \\
0.8\end{array}$ & $\begin{array}{r}+5.8 \\
6.3 \\
1 \cdot 4\end{array}$ & $\begin{array}{r}+9.2 \\
3.6 \\
0.8\end{array}$ & $\begin{array}{r}+2 \cdot 9 \\
12 \cdot 1 \\
2 \cdot 7\end{array}$ & $\begin{array}{r}+11.6 \\
11.9 \\
2.7\end{array}$ \\
\hline \multicolumn{10}{|c|}{ Ischaemic heart disease $(\%)$} \\
\hline $\begin{array}{l}\text { Mean } \\
\operatorname{SD}( \pm) \\
\operatorname{SE}( \pm)\end{array}$ & $\begin{array}{r}-16.5 \\
6.6 \\
1.5\end{array}$ & $\begin{array}{r}-8 \cdot 1 \\
8 \cdot 3 \\
1 \cdot 9\end{array}$ & $\begin{array}{r}+11 \cdot 4 \\
6 \cdot 7 \\
1 \cdot 5\end{array}$ & $\begin{array}{r}-12.5 \\
4.0 \\
0.9\end{array}$ & $\begin{array}{r}-6.5 \\
3.2 \\
0.7\end{array}$ & $\begin{array}{r}+I I \cdot 0 \\
5 \cdot 7 \\
I \cdot 3\end{array}$ & $\begin{array}{r}+\mathrm{II} \cdot 2 \\
5 \cdot 0 \\
\mathrm{I} \cdot \mathrm{I}\end{array}$ & $\begin{array}{r}+12.8 \\
10.6 \\
2.4\end{array}$ & $\begin{array}{r}+ \text { II.8 } \\
13 \cdot 4 \\
3 \cdot 0\end{array}$ \\
\hline $\begin{array}{l}\text { P value } \\
\text { Normal }\end{array}$ & $\stackrel{\star}{\text { heart di }}$ & e) & $\star$ & & & * & & * & \\
\hline
\end{tabular}

Note: SD, standard deviation; SE, standard error. Other abbreviations, see text. $\star$ P $<0.05$.

$Q-I$ is $Q$ to first sound. 
changes (\%), with standard deviations and errors, of each item studied before and after the drug in the two groups of subjects (normal and ischaemic heart disease).

A) Blood pressure and heart rate Blood pressure was decreased in the normal group (-10.7\%) and in the ischaemic heart disease group $(-16.5 \%)$; diastolic blood pressure was less decreased in the ischaemic heart disease group $(-8 \cdot 1 \%)$, but essentially unchanged in the normal group. Heart rate was increased by +20.4 per cent and $+\mathrm{Ir} \cdot 4$ per cent in the two groups.

B) Left ventricular systolic time intervals Ejection time was shortened by -14.6 per cent in the normal group and by -12.5 per cent in the diseased group, while ejection time index was reduced by 6.5 per cent in both groups. On the other hand, $Q-U$ and the $Q-U$ index (representing the pre-ejection period and its index) were prolonged, as in the Table. The $\mathrm{I}-\mathrm{U}$ (representing the isometric contraction time) was also prolonged $(+2.9 \%$ and
$12 \cdot 8 \%)$, as was Q-I ( $+11 \cdot 6 \%$ and $+11 \cdot 8 \%)$ in both groups.

C) Wave shapes (Fig. 2 and 3 ) In every case, the amplitude of the $A$ wave of the apex cardiogram was reduced by nitroglycerin and it approached the ventricular wave (shortened $A-C$ interval). In some cases, the A wave became indistinct or fused with the ventricular wave. The $A$ wave and the atrial sound on the phonocardiogram changed in parallel. Further, the systolic wave showed a midsystolic retraction, resulting in its steep fall from the $\mathrm{E}$ point.

The tidal wave of the carotid arterial pulse, which was distinctly evident before the drug administration, became indistinct afterwards, while the percussion wave became relatively peaked. The dicrotic wave increased, and the level of dicrotic notch declined. In some cases, the tidal wave disappeared completely, yielding a monophasic carotid wave.

2) Comparison of changes occurring in two groups after drug administration

Fig. 4 to 7 illustrate graphically the changes in

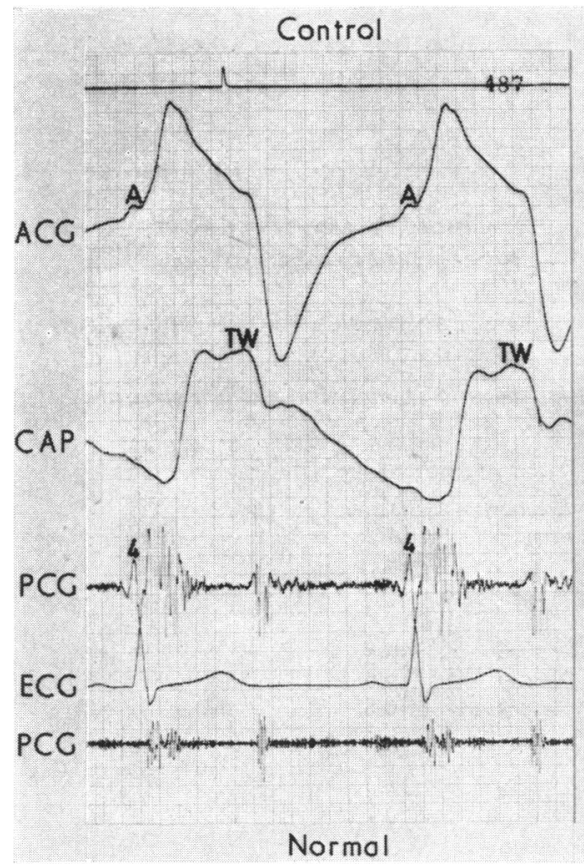

\section{$8 \mathrm{~min}$ after $0.6 \mathrm{mg}$ nitroglycerin}

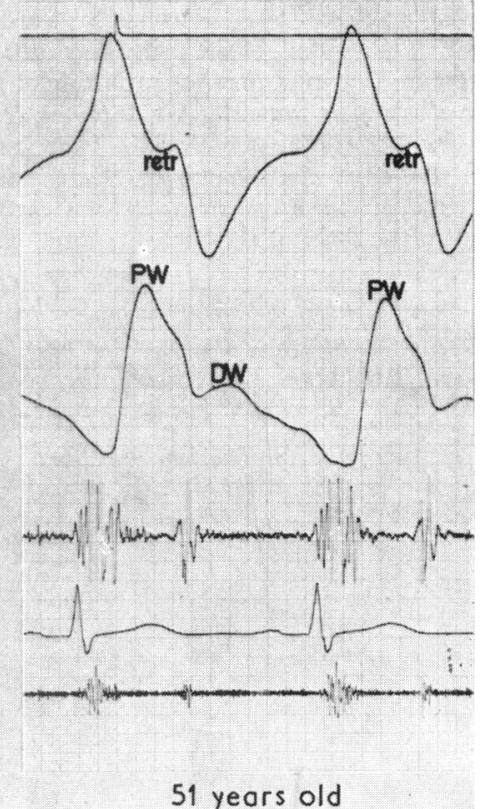

FIG. 2 Polygraphic tracings recorded from a 5I-year-old normal subject; a control tracing (left), and a tracing obtained 8 minutes after giving $0.6 \mathrm{mg}$ nitroglycerin (right), showing a diminution of ' $A$ ' wave with midsystolic retraction (retr) in the apex cardiogram, and a sharp fall with obscure tidal wave $(T W)$ and with relative increase in dicrotic wave (DW) in the carotid artery pulse on the right. 


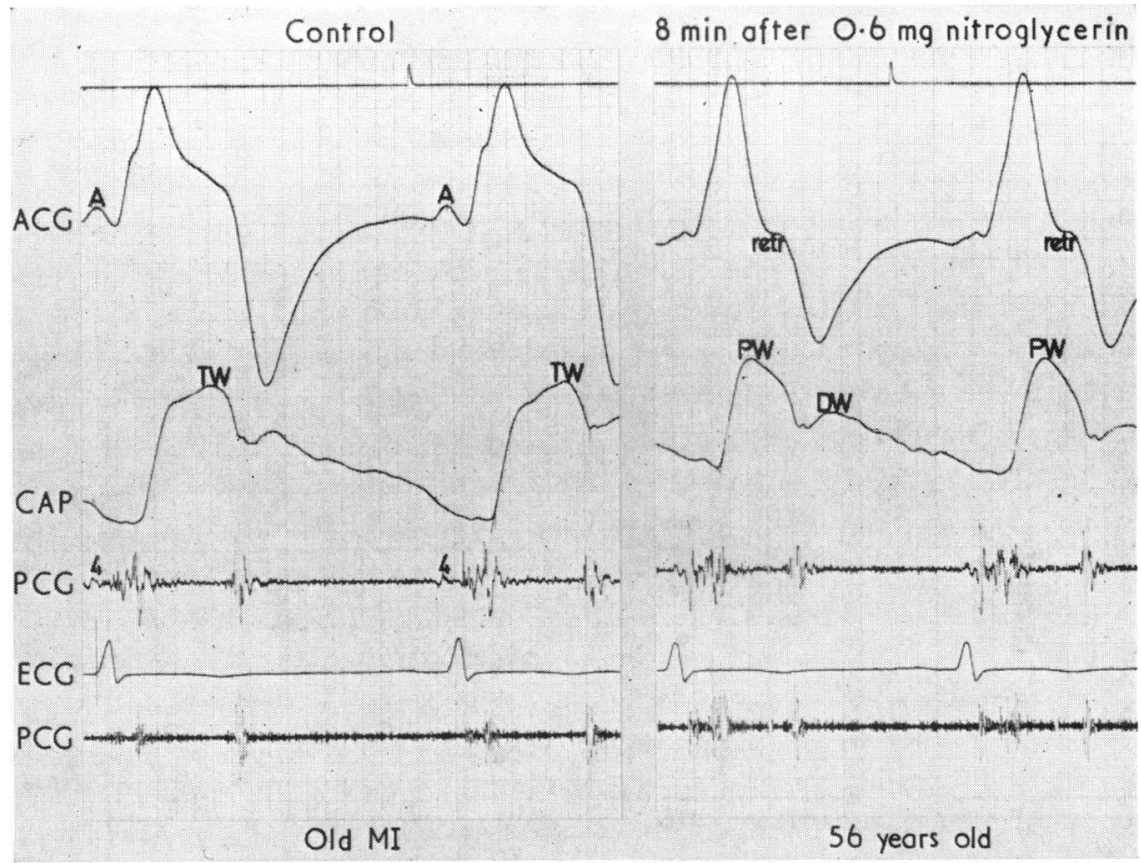

FIG. 3 Polygraphic tracings recorded from a 56-year-old patient with old myocardial infarction showing similar changes after nitroglycerin as in Fig. 2.
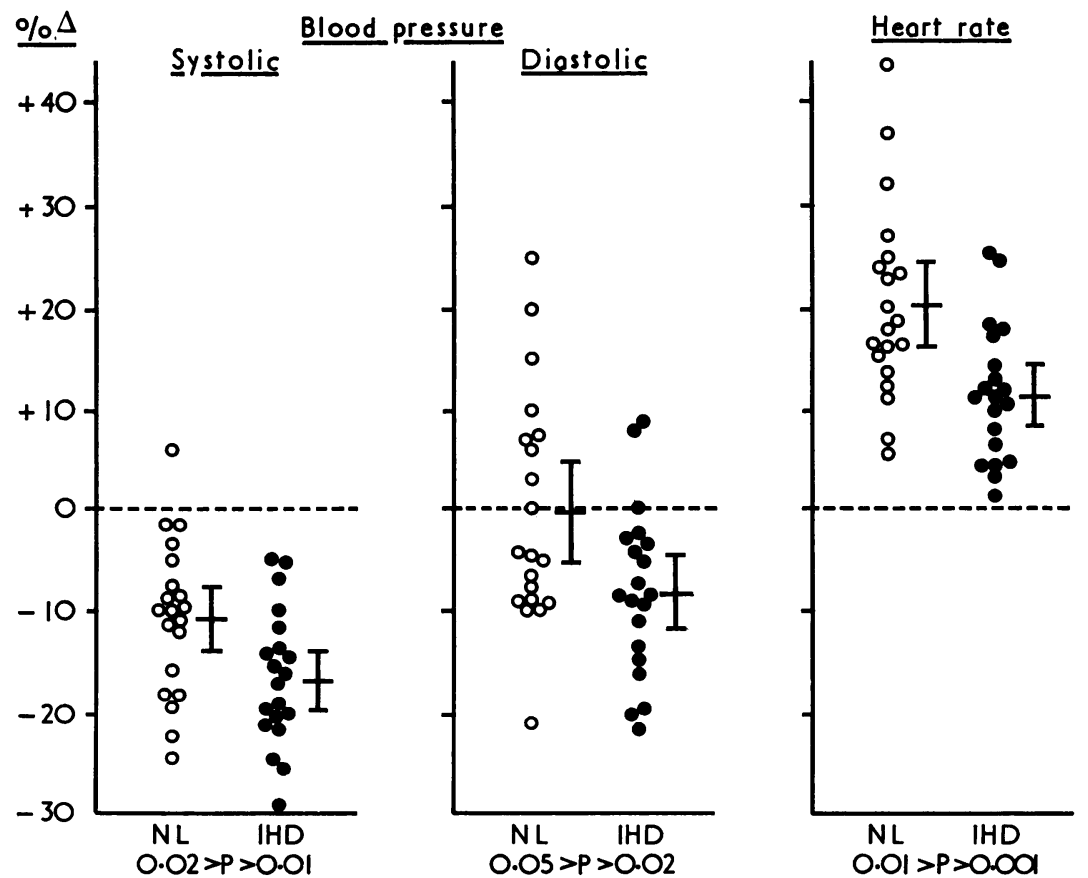

FIG. 4 Maximal percentage changes $(\% \Delta)$ in various haemodynamic parameters after nitroglycerin in the normal group (NL) and the diseased group (IHD), giving average value, standard error, and $P$ value. 


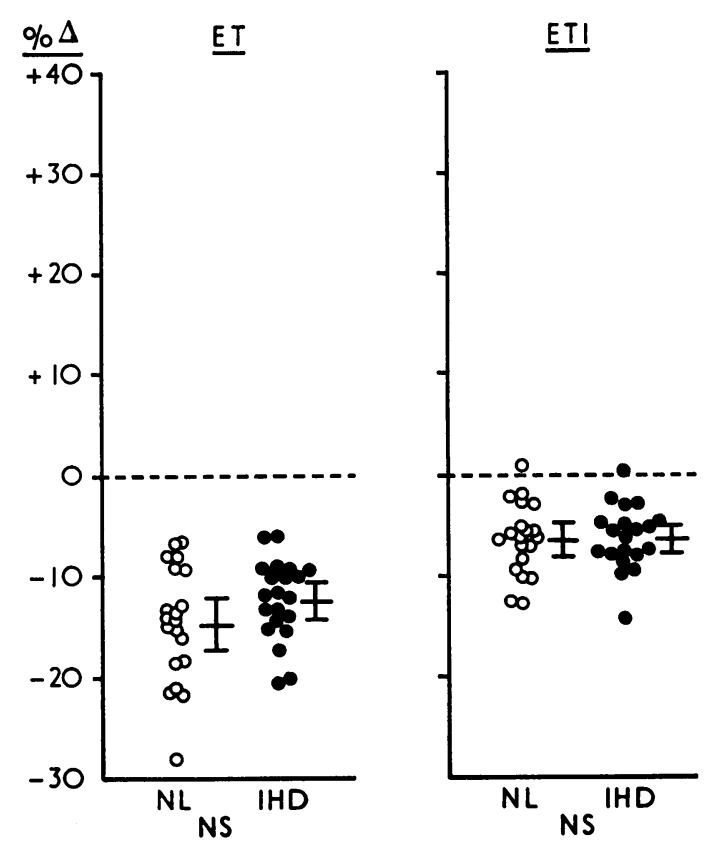

FIG. 5 Maximal percentage changes in ejection time (left) and ejection time index (right) after nitroglycerin between the two groups. NS=not significant.
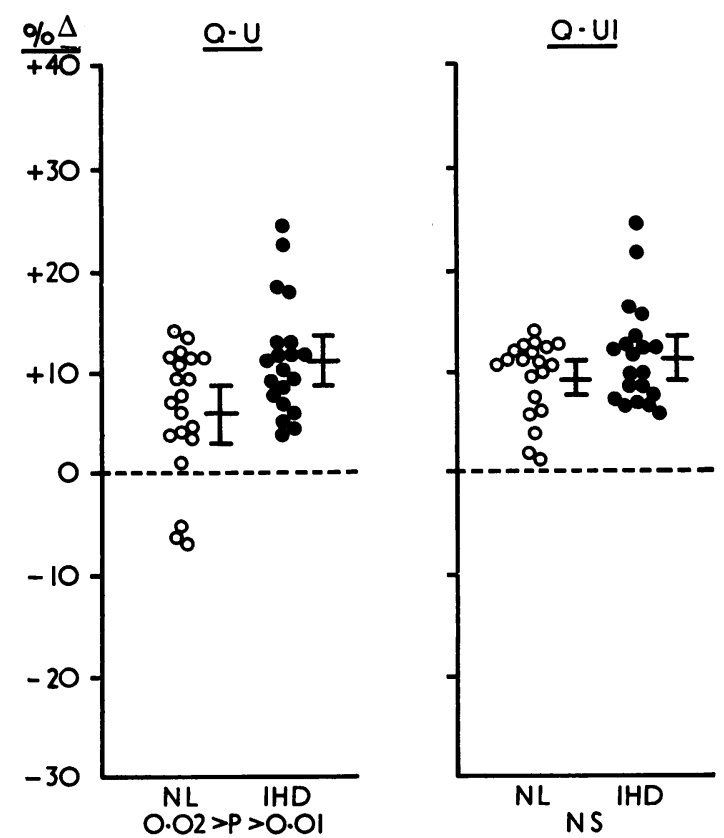

FIG. 6 Maximal percentage changes in $Q-U$ time (left) and $Q-U$ index (right) after nitroglycerin between the two groups.
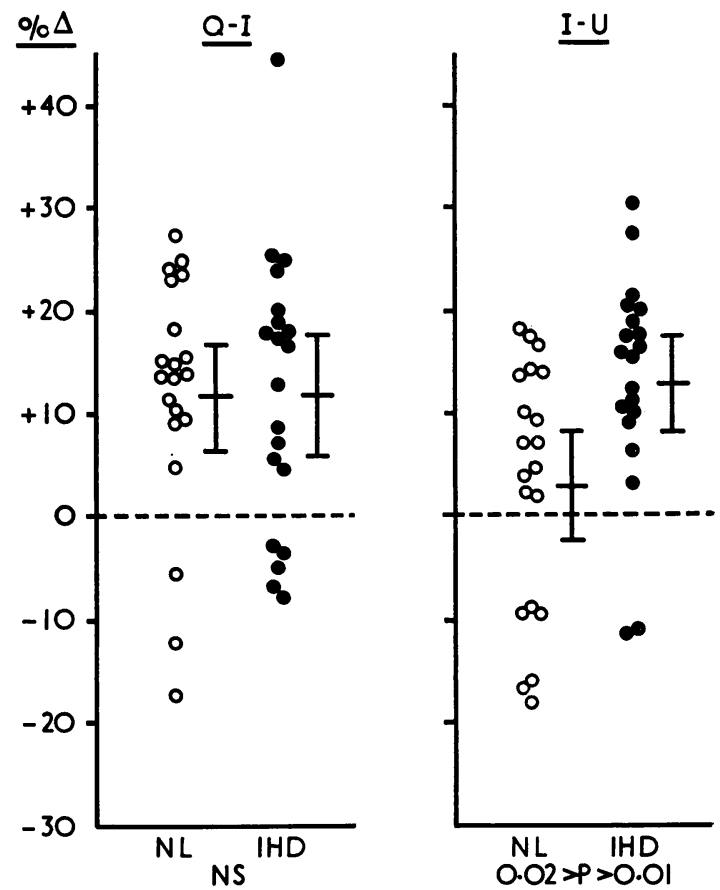

FIG. 7 Maximal percentage changes in $Q-I$ (left), and $I-U$ interval (right) after nitroglycerin between the two groups.

various haemodynamic parameters, induced by nitroglycerin in the two groups.

A) Blood pressure and heart rate (Fig. 4) The fall in both systolic and diastolic blood pressure in the group with ischaemic heart disease proved to be more pronounced $(\mathrm{P}<0.05)$ than in the controls. On the other hand, the increase in heart rate was more pronounced $(\mathrm{P}<0.05)$ in the normal group.

B) Left ventricular systolic time intervals (Fig. 5-7) The shortening of ejection time and ejection time index was not significantly different in the two groups (Fig. 5).

By contrast, the prolongation in $\mathrm{Q}-\mathrm{U}$, and $\mathrm{I}-\mathrm{U}$ proved to be more pronounced $(P<0.05)$ in the ischaemic heart disease group (Fig. 6-7) but the prolongation of $Q-I$, and of the $Q-U$ index, was not appreciably different in the two groups (Fig. 6-7).

\section{Discussion}

I) Changes in various parameters after nitroglycerin administration (Table)

The observed fall in blood pressure and rise in heart rate after nitroglycerin administration was consistent with previous reports (Gorlin et al., 1959; 
Parker et al., 197I), as was the greater fall in systolic than diastolic blood pressure.

There is, as yet, no report dealing with the effect of nitroglycerin on values of systolic time intervals. The shortening of ejection time occurring after nitroglycerin administration was not solely due to the increase in heart rate, since the ejection time index was also significantly decreased (Weissler, Harris, and White, 1963). This decrease in the ejection time index was undoubtedly due to the reduction of stroke volume (Weissler, Harris, and Schoenfeld, I968) usually caused by the drug (Gorlin et al., 1959; Christensson, Karlefors, and Westling, 1965).

The prolongation of the isometric contraction time, as indicated by measurements of $I-U$, might have suggested that the drug reduced cardiac contractility (Reeves et al., 1960; Metzger et al., 1970). However, though diastolic blood pressure was not appreciably changed, left ventricular end-diastolic pressure was undoubtedly reduced, in view of the reduced stroke volume and presumed sympathetic discharge induced by hypotension. This reduction of left ventricular end-diastolic pressure could have reduced the isometric contraction time (I-U) (Metzger et al., 1970).

After the administration of nitroglycerin, the amplitude of the $A$ wave of the apex cardiogram lessened and the $A$ wave merged with the ventricular wave. In addition, there occurred midsystolic retraction of the ventricular wave, with increased rate of descent from the $\mathrm{E}$ point. These findings were consistent with the fall of left ventricular enddiastolic pressure and decrease in the cardiac size already shown by invasive methods (Hoeschen et al., 1966; Lee, Sung, and Zaragoza, 1970).

The disappearance of the tidal wave, the fall of the dicrotic notch, and the larger dicrotic wave of the carotid arterial pulse after nitroglycerin were characteristic of the fall in peripheral vascular resistance induced by the drug.

\section{2) Comparison of effects of nitroglycerin in the two groups}

In the ischaemic heart disease group, as compared with the normal group, the increase in heart rate induced by nitroglycerin was less prominent, the fall in blood pressure greater, and the prolongation of $Q-U$ and $I-U$ intervals more pronounced. Other investigators have also reported similar differences in the effects of nitroglycerin on the diastolic blood pressure and heart rate of normal subjects and patients with heart disease (Gorlin et al., 1959; Parker et al., 1971).

The greater prolongations of $Q-U$ and $I-U$ intervals in the ischaemic heart disease group sug- gested that the effect of nitroglycerin on either the cardiac contractility, or on the left ventricular enddiastolic pressure, was greater in the diseased group. These results are similar to those obtained previously in studies using amyl nitrite (Sawayama et al., 1968, 1969). When amyl nitrite was inhaled, the cardiodepressant effect was greater in the diseased group than in the normal group. Further direct haemodynamic studies, correlated with left ventricular systolic time intervals, will be required to clarify the mechanism of these observed differences in the responses to the nitrite drugs.

We are grateful to Dr. Allan V. N. Goodyer, Professor of Medicine, Yale University School of Medicine, for his valuable advice, and to Miss Masako Kinoshita for statistical analysis.

\section{References}

Christensson, B., Karlefors, T., and Westling, H. (1965). Haemodynamic effects of nitroglycerin in patients with coronary heart disease. British Heart fournal, 27, $5 \mathrm{I}$ I.

Gorlin, R., Brachfeld, N., MacLeod, C., and Bopp, P. (1959). Effect of nitroglycerin on the coronary circulation in patients with coronary artery disease or increased left ventricular work. Circulation, 19, 705.

Hoeschen, R. J., Bousvaros, G. A., Klassen, G. A., Fam, W. M., and McGregor, M. (1966). Haemodynamic effects of angina pectoris, and of nitroglycerin in normal and anginal subjects. British Heart fournal, 28, 221.

Lee, S. J. K., Sung, Y. K., and Zaragoza, A. J. (1970). Effects of nitroglycerin on left ventricular volumes and wall tension in patients with ischaemic heart disease. British Heart Fournal, 32, 790.

Metzger, C. C., Chough, C. B., Kroetz, F. W., and Leonard, J. J. (1970). True isovolumic contraction time. Its correlation with two external indexes of ventricular performance. American fournal of Cardiology, 25, 434.

Parker, J. O., West, R. O., and Giorgi, S. di (1971). The effect of nitroglycerin on coronary blood flow and the hemodynamic response to exercise in coronary artery disease. American fournal of Cardiology, 27, 59.

Reeves, T. J., Hefner, L. L., Jones, W. B., Goghlan, C., Prieto, G., and Carroll, J. (1960). Hemodynamic determinants of the rate of change in pressure in the left ventricle during isometric contraction. American Heart fournal, 60, 745 .

Sawayama, T., Marumoto, S., Niki, I., and Matsuura, T. (1968). The clinical usefulness of the amyl nitrite inhalation test in the assessment of the third and atrial heart sounds in ischemic heart disease. American Heart fournal, 76, 746.

Sawayama, T., Ochiai, M., Marumoto, S., Matsuura, T., and Niki, I. (1969). Influence of amyl nitrite inhalation on the systolic time intervals in normal subjects and in patients with ischemic heart disease. Circulation, 40, 327.

Weissler, A. M., Harris, L. C., and White, G. D. (1963). Left ventricular ejection time index in man. Fournal of Applied Physiology, 18, 919.

Weissler, A. M., Harris, W. S., and Schoenfeld, C. D. (1968). Systolic time intervals in heart failure in man. Circulation, 37, 149.

Requests for reprints to Dr. Toshitami Sawayama, Cardiac Department, Kawasaki Medical School and Hospital, 2-I-80 Nakasange, Okayama City 700, Japan. 